\title{
Application of Augmented Reality (AR) Technologies in inhouse Logistics
}

\author{
Wei Wang ${ }^{1}$, Fei Wang ${ }^{2 *}$, Wei Song ${ }^{3}$, Shun $\mathrm{Su}^{4}$ \\ ${ }^{1}$ Research Institute of Highway Ministry of Transport, Beijing, 100088, China. \\ ${ }^{2}$ PCS Beratungscontor AG, Hamburg, 20459 Germany. \\ ${ }^{3}$ Johnson \& Johnson Vision Care, Ettlingen, 76275 Germany. \\ ${ }^{4}$ Department of Traffic Engineering and Transport Logistics, University of Kassel, Kassel, 34125 Germany.
}

\begin{abstract}
As a new information technology, mobile augmented reality (AR) technology has attracted more and more attention in recent years. Mobile AR uses mobile terminal, with the help of entity object recognition, obtains virtual information through calculation or in database, and superimposes virtual information on live video to realize the "enhancement" of virtual information to reality. In order to explore the application of AR technology in inhouse logistics, this paper analyses the principle and technical characteristics of AR technology. By analysing the application status of AR technology in inhouse logistics, the application advantages of AR technology in inhouse logistics are obtained. This paper summarizes 36 cases of AR technology application in inhouse logistics, summarizes and analyses the application prospect of AR technology in inhouse logistics. The functions of AR technology in the process of receiving, storage, sorting, transportation, inventory and planning are put forward. It provides theoretical guidance for the practical application of AR technology in inhouse logistics.
\end{abstract}

\section{Introduction}

Augmented reality (AR) is one of the new technologies, which attracts more and more attention. Based on computer generated visualizations and 3D model projections, AR could augment the environment in real world with additional and valuable virtual information (such as text, video, sound, etc.), so that human senses and abilities can be enriched. Although, the application of AR in logistics is still in its infancy, it is still regarded as one of the technologies that could bring the "next big wave of change" in the logistics industry[1]. Meanwhile, using AR can lead to considerable increase of efficiency and a lower error rate compared to conventional picking methods[2]. This study can provide theoretical reference for the combination of AR technology and logistics industry.

\section{General basis of AR}

The beginning of AR can date back to Sutherland's work in the 1960s, however only over the past decades has there been enough work to refer to AR as a research field.18 In 1994 Milgram and Kishino introduced a reality-virtuality continuum (Figure 1), which defined AR as one part of mixed reality (MR) between Virtual Environment (VE) and Real Environment (RE)[3]. Neither like VE, in which the user only interacts with $3 \mathrm{D}$ digital objects and is completely immersed in a virtual world, nor like RE, where none of the user's view is replaced by virtual content, $\mathrm{AR}$ is the merging together of real and virtual worlds[4].

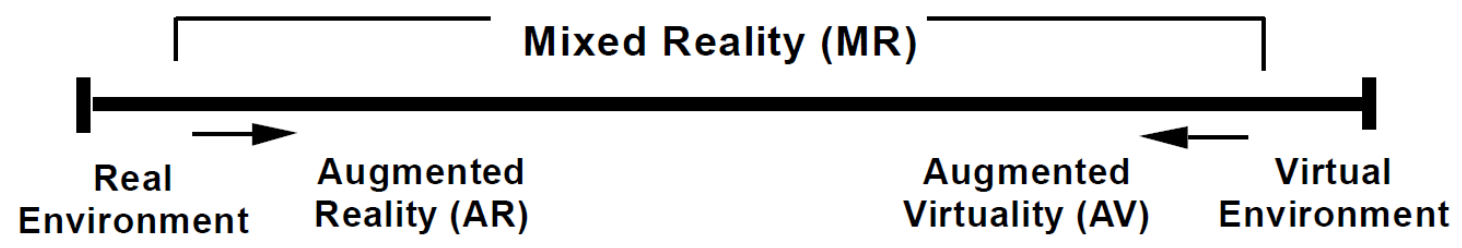

Figure 1: Reality - Vitality Continuum[3]

With these features, AR is regarded as the expansion of physical reality by overlaying digital or computergenerated information, such as image, audio, video and touch or haptic sensations on a user's view of the real-time environment[5]. The basic AR concept is not complicated and can be summarized by four basic and distinct tasks:(1) Scene capture. (2) Scene identification. (3) Scene processing. (4) Scene visualization.

This process can be illustrated as showed in Figure 2. The user's view is recorded by a mini camera attached to

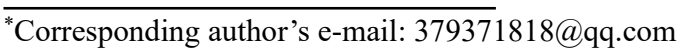


the Head-mounted Displays (HMD). This original image is transferred to a wearable PC which is the core of running the AR system. The AR system searches then the image for AR markers, identifies the position of markers and add the additional information (in this example the texts), correctly onto the original image that really exists. The final picture in the HMD displays then the newly created image[6].

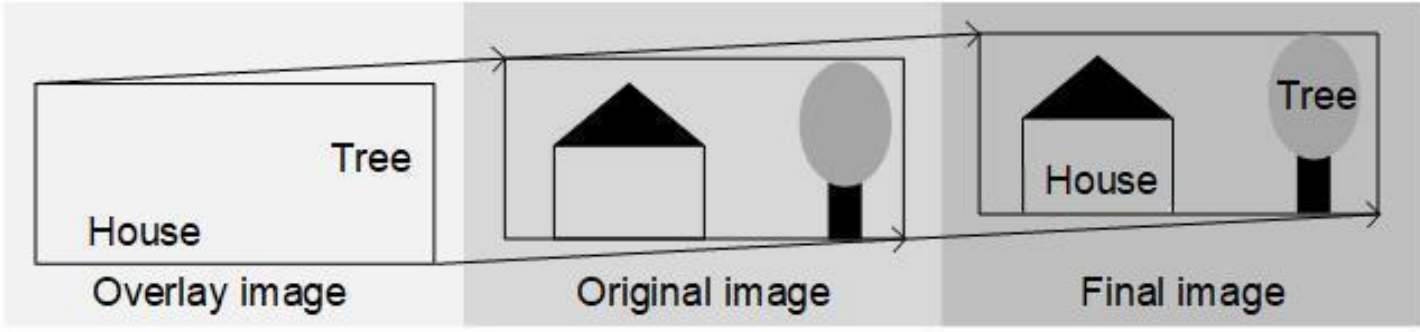

Figure 2: Illustration of the AR concept[6]

\section{$3 \quad A R$ in logistics}

\subsection{Driver of AR application in logistics}

The world is always in a permanent transition. Different kinds of emerging technologies have massive influence on the traditional logistics.64 By applying innovative technologies, logistics companies are not only able to optimize the efficiency that cannot be achieved by human works, but also help redefine their behaviors and practices, take operations from reactive to proactive, process from manual to autonomous, and serve from standardized to personalized[7][8].

Due to the constantly increased level of automation in production and logistics, the demand to integrate human into the work process with digitalized equipment is also increasing [5]. Nowadays, most of the processes in inhouse logistics, such as storage and stock removal are fully automated. For instance, the completely automated transportation system has tremendously optimized the efficiency of warehousing process. There are still some processes in logistics to be improved, where the automation is not highly implemented and performance still largely depends on human decisions, experience, expertise or even mood. For example, in order picking area, the employees usually need to perform several actions consecutively in order to successfully pick an order. Specifically, the picker must firstly find the right product, then he must scan it before taking the right amount to the loading dock following some certain orders. These series of operations require the pickers to have constant concentration and high level of proficiency. Thus, mistakes arise from these manual operations quite often, even though the picker has repeated the same work for thousand times. This process is very important in inhouse logistics, which may have a huge impact on the quality of delivery and the relationship between customers and suppliers. Errors caused by employees will negatively influence the business at company level, possibly lead to financial consequences[9]. Although support systems such as Pick by Voice or Pick by Light help minimize the existing problems caused by human failure in this area, they both have their limitations in terms of functionalities and the way to interact with employees[9]. Thus, new concepts that are based on modern technology for visualization of information and flexible interaction between human and systems in the surrounding environment is requested[10].

Various technologies can provide a suitable basis for facilitating the exchange of information between humans and machines, and reduce the workload and simplify daily routine. AR is one of the promising options. As introduced previously, with the help of scene recognition and virtual information generated by AR system, it enables to identify the location of a product autonomously and show the best route to move to the next product at a faster pace[11]. The displayed instructions are implemented in workflows where complex and rapidly changing tasks take place. Not only limited to this, AR device can also give workers hand-free approach to get things done and provide remote help from other colleagues to fix complex issues. All these mentioned functions benefit the operations, troubleshooting and error reducing in logistics.

\subsection{Identification of $A R$ application in inhouse logistics}

Generally, AR can be used in many human-operated areas of logistics, where handling errors could be considerably diminished with additional provided information. Although the available literature is limited, a practiceoriented use cases of AR application in inhouse logistics can still be summarized, which cover good receipt, storing picking, shipping and inventory. Besides, many valueadded services in logistics are also benefit from AR application.

By far, order picking is the area, where most research in terms of AR application in logistics can be found. Due to its operational complexity and economical relevance (more than $50 \%$ of warehousing costs incurred in picking area)[12], it is also the field where huge potential of process optimization in logistics exists. Previous research mainly focused on how an operator could be aided by using AR[13], what is the most effective way to indicate a storage location to a picker[14]. DHL report "Augmented Reality in logistics" indicated that companies like Knapp, SAP, and Ubimax tried to use AR systems to integrate different functions together, such as real-time object recognition, barcode reading, indoor navigation and etc., in order to achieve fast, error-free and user friendly picking process[15]. 
In order to have an idea of how AR application works, here are some screenshots of AR interfaces integrated in Figure 3.
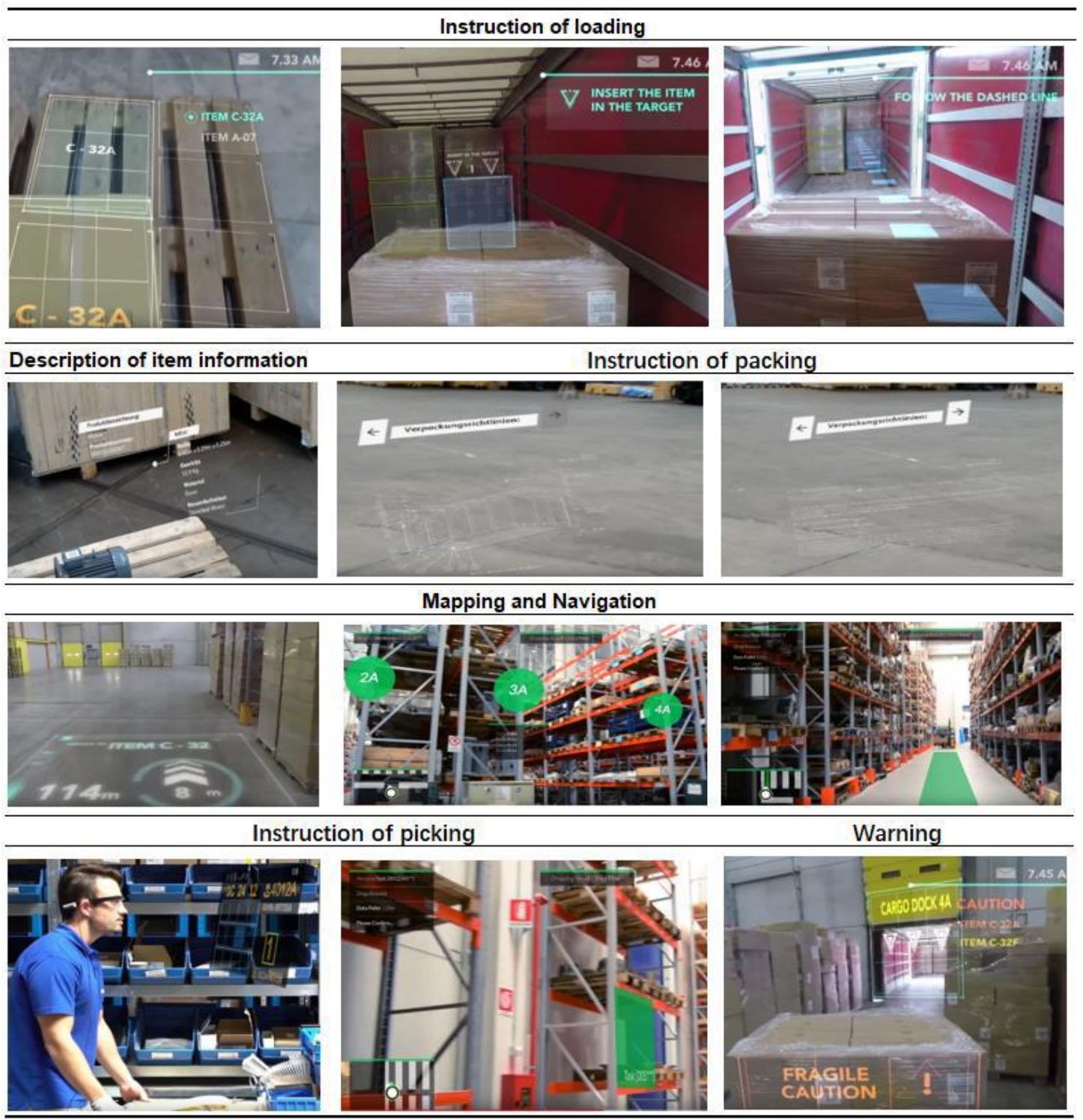

Figure 3: User interface of some typical AR applications in logistics[16]

\subsection{Summary of all potential use cases of $A R$ in inhouse logistics}

Relevant studies of AR application for the other key operations, i.e. good receipt, storing, shipping and inventory are more limited and usually presented through some online reports or news. A short description of each applicable use cases of AR and its areas are summarized in Table 1. By reviewing their studies, some potential use cases in the mentioned areas are derived in following parts[1][6][9][11][14][15][17][18][19].

Table 1: AR use cases in inhouse logistics

\begin{tabular}{llll}
\hline No. & Use case & Description & Area \\
\hline 1 & $\begin{array}{l}\text { Monitor/record } \\
\text { processes }\end{array}$ & $\begin{array}{l}\text { Acquisition of process data; Provision for } \\
\text { evaluation of KPIs }\end{array}$ & All inbound areas \\
2 & $\begin{array}{l}\text { Display evaluations } \\
\text { Evaluation of process data; Analysis of KPIs is } \\
\text { displayed as a report on smart glasses } \\
\text { A reward symbol is displayed when achievement } \\
\text { of certain services is reached by the carrier }\end{array}$ & $\begin{array}{l}\text { Display reward } \\
\text { symbols }\end{array}$ & All inbound areas \\
\hline
\end{tabular}


Prioritize deployment

4 on process metrics

5

6

Display current workload Display and translate texts

Display instructions for operation

Assist learning phase through instructions

Display test plans

(Value Added

Services)

Support video transmission / streaming

Guide work steps by remote control (internal support) Guide work steps by remote maintenance (external support) Support video communication with customers

Document process execution

\section{Document damage}

Recognize and display input errors

Support automated examination

Conduct automated examination of picking Conduct automated review of advertisement Conduct automated inspection of the object condition

Conduct automated examination of hazardous goods

Identify Object with object recognition

Scan barcodes and QR codes
Demand-driven control of employees based on

process metrics (e.g., current utilization). When certain events occur (for example, a high degree of utilization), employees are accordingly prioritized differently Display of the workload in real time (selfmanagement)

Recognizing text, translating text, visualizing text Instructions for handling goods and operation instructions (orders) are conveyed to the employee via the glasses. The instructions can be displayed in the form of checklist, pictures, videos etc.

Support a new employee during training (for example, by displaying individual work process step by step)

Providing (possibly multilingual) information for implementation

Use the glasses for video conferencing from the user's point of view; Data glasses are used as a tool for the guidance and support of certain process steps

Data glasses are used as a tool for the internal guidance and support for certain process steps (for example, warehouse revision)

Data glasses are used as a tool for external guidance and support for certain process steps (e.g. forklift maintenance)

Using glasses for real-time video documentation with customers from the user's point of view (e.g. damage)

Documentation of processes from the user's point of view (e.g. high-quality goods)

Document damages by using camera and transfer them to the damage management (for example entrance control)

Detect errors and give feedback to the employee (e.g. based on the user's input on the smart glasses)

Detect errors and give feedback to the employee (e.g. based on image recognition of camera)

(Camera-based / sensor-based) Examine if e.g. the right picking shelf has been operated by the employee

Camera-based examination of advertisement stands (e.g. through image recognition)

Camera-based inspection for damage and completeness

Camera-based examination when handling dangerous goods (e.g. warning if the distance between two containers of dangerous goods is too short)

Compare and identify object based on stored features (color, size, geometry)

Identify object by scanning machine-readable codes
All inbound areas

All inbound areas

All inbound areas

All inbound areas

All inbound areas

All inbound areas

All inbound areas

All inbound areas

All inbound areas

All inbound areas

All inbound areas

All inbound areas

All inbound areas

All inbound areas

Picking

All inbound areas

Good receipt, Shipping \& handling

Good receipt, Shipping \& Handling, Inventory

All inbound areas, except inventory

All inbound areas, except inventory 


\begin{tabular}{|c|c|c|c|}
\hline 24 & $\begin{array}{l}\text { Display information } \\
\text { about object }\end{array}$ & Show additional information about object & $\begin{array}{l}\text { All inbound areas, } \\
\text { except inventory }\end{array}$ \\
\hline 25 & $\begin{array}{l}\text { Display navigation } \\
\text { instructions (static) }\end{array}$ & $\begin{array}{l}\text { Navigate an employee e.g. by displaying arrows, } \\
\text { maps, instructions }\end{array}$ & $\begin{array}{l}\text { Goods receipt, } \\
\text { Warehousing }\end{array}$ \\
\hline 26 & $\begin{array}{l}\text { Display real-time } \\
\text { maps with traffic } \\
\text { information } \\
\text { (dynamic) }\end{array}$ & $\begin{array}{l}\text { Display maps and additional information (e.g. } \\
\text { about the traffic situation in the warehouse) so } \\
\text { that driving decisions can be made on that basis }\end{array}$ & $\begin{array}{l}\text { Goods receipt, } \\
\text { Warehousing }\end{array}$ \\
\hline 27 & $\begin{array}{l}\text { Display object- } \\
\text { related warning and } \\
\text { safety information }\end{array}$ & $\begin{array}{l}\text { Warning or safety instruction is transmitted to the } \\
\text { employee with help of acoustic, optical or haptic } \\
\text { signals to the object }\end{array}$ & $\begin{array}{l}\text { All inbound areas, } \\
\text { except inventory }\end{array}$ \\
\hline 28 & $\begin{array}{l}\text { Display process- } \\
\text { related warning and } \\
\text { safety information }\end{array}$ & $\begin{array}{l}\text { The employee is provided with general or } \\
\text { process-related warning or safety instruction by } \\
\text { acoustic, optical or haptic signals }\end{array}$ & $\begin{array}{l}\text { All inbound areas, } \\
\text { except inventory }\end{array}$ \\
\hline 29 & Capture location & Capture location of object & Warehousing \\
\hline 30 & Find object & $\begin{array}{l}\text { Find object (among others shipping unit, items, } \\
\text { shipping container) }\end{array}$ & Picking \\
\hline 31 & $\begin{array}{l}\text { Show stacking / } \\
\text { packing information }\end{array}$ & $\begin{array}{l}\text { Provide information and instructions on if and } \\
\text { how one object can be stacked / packed in the best } \\
\text { possible way }\end{array}$ & $\begin{array}{l}\text { Shipping \& } \\
\text { Handling }\end{array}$ \\
\hline 32 & $\begin{array}{l}\text { Measure and } \\
\text { document object }\end{array}$ & Use data glass for optical measurement of object & Goods receipt \\
\hline 33 & $\begin{array}{l}\text { Show optimal storage } \\
\text { position }\end{array}$ & $\begin{array}{l}\text { For a package, it can be indicated where the } \\
\text { optimal storage container is }\end{array}$ & Warehousing \\
\hline 34 & $\begin{array}{l}\text { Display and control } \\
\text { picking list }\end{array}$ & $\begin{array}{l}\text { Support with the picking process via picking list } \\
\text { and (automatic) confirmation }\end{array}$ & Picking \\
\hline 35 & $\begin{array}{l}\text { Display loading } \\
\text { optimization }\end{array}$ & $\begin{array}{l}\text { Display optimized loading sequence so that the } \\
\text { load space can be fully used }\end{array}$ & $\begin{array}{l}\text { Shipping \& } \\
\text { Handling }\end{array}$ \\
\hline 36 & $\begin{array}{l}\text { Record inventories } \\
\text { automatically }\end{array}$ & $\begin{array}{l}\text { Capturing the number of available objects in the } \\
\text { warehouse (image recognition) }\end{array}$ & Inventory \\
\hline
\end{tabular}

All together 36 use cases in inhouse logistics were noted in literature. These 36 use cases were inductively categorized according to their respective process groups as well as their function groups. Among them, 18 use cases, which are mostly categorized in management and communication, can be applied in whole logistics process. There are also specific uses cases only for respective logistics areas. Here is an overview about the number of use cases (Figure 4).

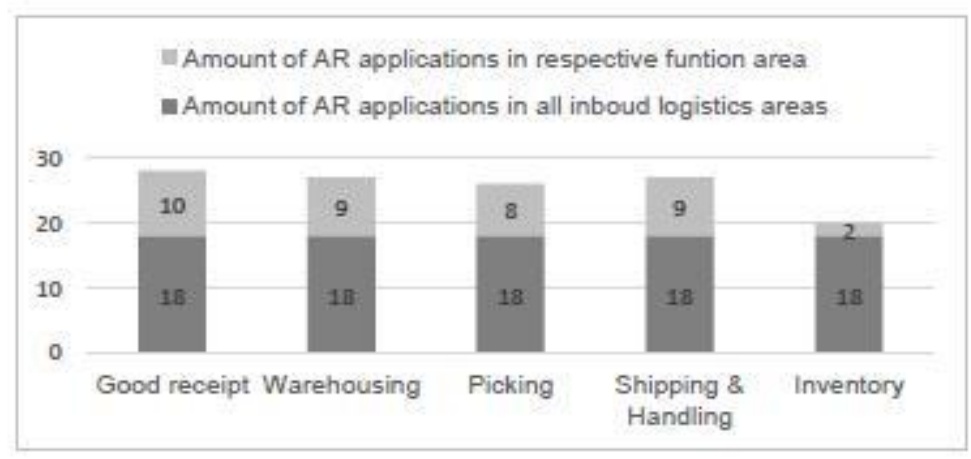

Figure 4: Amount of AR applications in inhouse logistics

\section{Application prospect of AR technology in Logistics}

According to the characteristics of mobile AR technology and logistics business, this paper discusses the application prospect of AR technology in logistics from five aspects.

\subsection{AR application in good receipt}

Good receipt is the first station of inhouse logistics, where different kinds of goods with different quantities are gathered. Unloading them from the truck, transferring to the container used intern, and checking the quality before 
shipping to the warehouse are the main tasks to be completed. In order to minimize the burden of the employees, AR could

- Scan product information.

- Activate automated inspection of the received product, in order to check the quality and quantity against delivery note.

- Display unloading information.

- Display transhipping guideline with step-by-step instructions on how to most efficiently unload a container according to the size, dimension, and weight.

\subsection{AR application storing/warehousing}

This function area of logistics mainly deals with the tasks like, identifying the article, transporting to warehouse, and storing items in the warehouse. The objectives are to create short throughput times, achieve high process quality and increase flexibility in storage. Thus, AR could

- Inform an operator about a new allocated task.

- Display optimal storage location of incoming items.

- Display picture and details of the item to be stored.

- Display real-time maps with traffic information (dynamic).

- Indicate best route to storage location.

- Indicate picker's current status as well as next step of the process.

- Check locations requiring replenishment while storing.

- Book the goods in warehouse management system.

\subsection{AR application in picking}

The order picking is a basic warehousing process and has an important influence on supply chain's productivity. Therefore, huge potential and benefit of AR application are meant to implement in this area. The process of picking was demonstrated in previous sections, here is no more tautology. The operator here can acquire all the information about the environment from the warehouse system through AR device. The system collects information about the user-related work orders and shows them directly to the operator through AR interfaces. Based on this, AR could

- Inform an operator about a new task allocated to him.

- Display picture and details of the item to be picked.

- Display the storage location of the item to be picked.

- Display picking route.

- Highlight the physical location with the item required.

- Inform about errors and disruptions.

- Scan the item's barcode to assign to picking cart or to see more information.
- Highlight where to put each item on the picking cart for sorting while picking.

- Give information to prevent congestion in aisles.

- Monitor picker's condition and performance.

With these applications, pickers can work freehand and paperless. All orders reach the employees on site in real time, and every movement of goods is immediately updated in the warehouse management system. In addition, warehouse staff can easily and quickly get access to the status of the orders.

\subsection{AR application in shipping \& handling}

The items that will be sent out to customers are gathered and packed here. Depending on the requirement of customers or intern standards, they are differently handled. Essentially, the common feature is that the packages of a consignment must be cleared and loaded until the departure time of the truck. In order to support this process, AR could

- Show what type of cardboard to use.

- Show the best way to place picked items in a package.

- Indicate the right location/pallet for the shipment.

- Show where to place each order on a pallet/in a truck according to type of orders, destination, fragility.

- Indicate appropriate loading area.

- Check products to be loaded on a truck.

\subsection{AR application in inventory and warehouse planning}

Through AR device, the employee can not only receive the scheduled inventory product list, but also get a warehouse overview and detailed item description. Only if a product is at the right place, a positive feedback can be displayed. For the inventory purpose, AR could

- Show stacking/packing information

- Capture the number of available objects in the warehouse

In real industry environment, production lines and logistics networks need to be adapted constantly and the demand for frequent rebuilding is also inevitable. Thus, planning tools with possibilities for generating or designing a detailed and well-proven model for warehouse systems before the project's realization are required. This will not only save money, but also allow logistics planners to fully test their plans before implementing it. With the help of AR devices, AR could help logistics planners to

- Visualize next warehouse in full-scale before even beginning construction.

- Model workflows through the facility, test measurements, all virtually.

\subsection{AR application in inhouse logistics for other purposes}

In addition to identifying the AR application in logistics function areas, Niemöller78 also categorized the potential 
use cases of AR application according to their process groups in logistics, which include management, communication, value-aided-service/quality assurance. It is to be noting that the assignment of one use case to one process group is not always possible, since certain use cases occur in several logistics processes. For example, displaying the information of products can be applicable in all logistics processes.

\section{Management}

The use of AR also makes possible for monitoring employees. The process data and workflows during each activity can be recorded continuously. Thus, the modeling of the processes is possible while the employees carry out their activities. For example, AR can show the evaluations of a picker based on the daily performance in the picking and assign the tasks for every individual picker according to the real-time workload or priority of the tasks in the picking area.

\section{Communication}

Communication, as an assist use case, can be used in the form of displaying checklists for order picking, or for inspection plans for inventory. By enabling bidirectional video transmission/streaming, third parties are allowed to access the view of the AR users (e.g., for the purpose of internal or external remote maintenance). In addition, AR can also simplify the communication through the translation of texts or by pictographs. (QA).

Value added services (VAS) and quality assurance

The use of AR can also make automated control in logistics come true. In this case, not only the error detection and feedback to the employee can take place, but also the errors caused by employees while inputting the information can be detected and reported. Particularly for quality assurance, the documentations of damages and automated forwarding to quality management are the potential application scenarios.

Phase-specific use cases.

The main use case here is identification, which represents a collection of key functions including the recognition of objects based on saved characteristics, such as color, size and geometry, as well as the identification via bar and QR code. Furthermore, the inserted navigation function offers employee the possibility to obtain both static and dynamic navigation instructions. For example, employee can choose the best route to the target location with the aid of displayed maps of warehouse and real-time traffic information in order to avoid accidents or congestion. Usages of AR in the area of security can be realized by showing warning and safety instructions, e.g. the risk of breakage of individual articles, or processrelated safety instructions. In both cases, the acoustic, optical or haptic signals can be used for the warning message.

\section{Conclusion and discussion}

The application of AR technology in logistics can not only save labor cost and improve logistics efficiency, but also make the whole process automation control of logistics become a reality. However, at present, the application of
AR technology in logistics is still in its infancy. Although many AR systems for logistics have been developed, there are few large-scale applications. Most logistics enterprises are still cautious about the use of this technology, mainly due to the lack of decision-making level, enterprises can not determine whether this new technology will bring opportunities or disasters in the future logistics industry. Therefore, in the next stage of research, it is necessary to put forward the relevant factors that should be considered in the application of AR technology in logistics, and build a decision-making model to help the managers of logistics enterprises make reasonable and scientific decisions.

\section{References}

1. Stoltz, M.-H. et al. (2017): Augmented Reality in Warehouse Operations. Opportunities and Barriers. In IFAC-PapersOnLine 50 (1), pp. 12979-12984.

2. Zobel, B. et al. (2016): Augmented Reality am Arbeitsplatz der Zukunft: Ein Usability-Framework für Smart Glasses. In Informatik, pp. 1727-1740.

3. Milgram, P. et al. (1994): Augmented Reality: A class of displays on the reality-virtuality continuum. In Telemanipulator and Telepresence Technologies 2351, pp. 282-292.

4. Azuma, R. et al. (2001): Recent advances in augmented reality. In IEEE Comput. Grap. Appl. 21 (6), pp. 34-47.

5. Peddie, J. (2017): Augmented reality. Where we will all live. Cham: Springer.

6. Mueck, B. et al. (2005): Aumented Reality applications for Warehouse Logistics. In Ajith Abraham, Yasuhiko Dote, Takeshi Furuhashi, Mario Köppen, Yukio Ohsawa, Azuma Ohuchi (Eds.): Soft Computing as Transdisciplinary Science and Technology. Proceedings of the fourth IEEE International Workshop WSTST '05. Berlin, Heidelberg: Springer-Verlag Berlin Heidelberg (Advances in Soft Computing, 29), pp. 1053-1062.

7. Gesing, B.; J. Peterson, S. (2018): Artificial intelligence in logistics. A collaborative report by DHL and IBM on implications and use cases for the logistics industry. Troisdorf. Available online at https://www.logistics.dhl/content/dam/dhl/global/cor e/documents/pdf/glo-ai-in-logistics-white-paper.pdf, checked on $5 / 20 / 2018$.

8. Robinson, A. (2016): Augmented Reality Supply Chain is Here and It's Going to be Effective. Cerasis. Available online http://cerasis.com/2016/02/10/augmented-realitysupply-chain, checked on 6/19/2018.

9. Reif, R.; Walch, D. (2008): Augmented \& Virtual Reality applications in the field of logistics. In TVC 24 (11), pp. 987-994.

10. Mättig, B. et al. (2016): Untersuchung des Einsatzes von Augmented Reality im Verpackungsprozess unter Berücksichtigung spezifischer Anforderungen an die Informationsdarstellung sowie die ergonomische Einbindung des Menschen in den 
Prozess. Fraunhofer-Institut für Materialfluss und Logistik IML.

11. Merlino, M.; Sproge, I. (2017): The Augmented Supply Chain. In Procedia Engineering 178, pp. 308318.

12. Giannikas, V. et al. (2017): An interventionist strategy for warehouse order picking: Evidence from two case studies. In International Journal of Production Economics 189, pp. 63-76.

13. Reif, R.; Günthner, W. (2009): Pick-by-vision. Augmented reality supported order picking. In Vis Comput 25 (5-7), pp. 461-467.

14. Schwerdtfeger, B.; Klinker, G. (2008): Supporting order picking with augmented reality. In IEEE Staff (Ed.): 2008 7th IEEE International Symposium on Mixed and Augmented Reality. Place of publication not identified: I E E E, pp. 91-94.

15. Glockner, H. et al. (2014): Augmented reality in logistics. Changing the way we see logistics - a DHL perspective. Available online at http://www.dhl.com/content/dam/downloads/g0/abo ut_us/logistics_insights/csi_augmented_reality_repo rt_290414.pdf, checked on 6/13/2018.

16. https://www.youtube.com/watch?v=3YqaRrzkM4c

17. Niemöller, Christina; Zobel, Benedikt; Berkemeier, Lisa; Metzger, Dirk; Werning, Sebastian; Adelmeyer, Thomas et al. (Eds.) (2017): Sind Smart Glasses die Zukunft der Digitalisierung von Arbeitsprozessen? Explorative Fallstudien zukünftiger Einsatzszenarien in der Logistik. 13th International Conference on Wirtschaftsinformatik. St. Gallen, February 12-15.

18. Martin, R. (2015): How to make best use of augmented reality in supply chain? Supply Chain Asia. Available online at

19. http://supplychainasia.org/how-to-make-best-use-ofaugmented-reality-in-supply-chain/, checked on 6/20/2018.

20. Cirulis, A.; Ginters, E. (2013): Augmented Reality in Logistics. In Procedia Computer Science 26, pp. 14 20. 